\title{
Optimization of Diffusion Bonding of Pure Copper (OFHC) with Stainless Steel 304L
}

\author{
Ahmed Ali Akbar Akbar* \\ Sami Abualnoun Ajeel** \\ Safaa Mohammed Hassoni**** \\ *,**Department of Production Engineering and Metallurgy/University of Technology \\ ***Institute of Technology Baghdad/Middle Technical University \\ ***Email: as_5599@yahoo.com
}

(Received 10 April 2017; accepted 28 November 2017)

https://doi.org/10.22153/kej.2018.11.002

\begin{abstract}
This work deals with determination of optimum conditions of direct diffusion bonding welding of austenitic stainlesssteel type AISI 304L with Oxygen Free High Conductivity (OFHC) pure copper grade (C10200) in vacuum atmosphere of $\left(1.5 * 10^{-5} \mathrm{mbr}\right.$.). Mini tab (response surface) was applied for optimizing the influence of diffusion bonding parameters (temperature, time and applied load) on the bonding joints characteristics and the empirical relationship was evaluated which represents the effect of each parameter of the process. The yield strength of diffusion bonded joint was equal to $153 \mathrm{MPa}$ and the efficiency of joint was equal to $66.5 \%$ as compared with hard drawn copper. The diffusion zone reveals high microhardness than copper side due to solid solution phase formation of $(\mathrm{CuNi})$. The failure of bonded joints always occurred on the copper side and fracture surface morphologies are characterized by ductile failure mode with dimple structure. Optimum bonding conditions were observed at temperature of $650{ }^{\circ} \mathrm{C}$, duration time of $45 \mathrm{~min}$. and the applied stress of $30 \mathrm{MPa}$. The maximum depth of diffuse copper in stainless steel side was equal $11.80 \mu \mathrm{m}$.
\end{abstract}

Keywords: Diffusion bonding, Pure copper, Stainless steel, 304 L.

\section{Introduction}

Joining dissimilar metals demands for increasing importance in many applications to utilize hybrid structures and compounds properties like high strength, thermal conductivity and good corrosion resistance [1]. The applications of dissimilar metals such as austenitic stainless steel- coppers (OFHC) are widely used in traditional and nuclear power plants [2]. However, the welding of austenitic stainless steel with copper alloys by conventional welding processes is not recommended by these methods because of probability of formations of newly intermetallic compounds at the weld pool. Copper and its alloys are majorly utilized for pipelines of heat exchangers; valve and clad plate for steel hulls of small ships, etc. alloys of copper have enough resistance corroded in seawater [3]. Broadly, the application of Austenitic stainless steel to copper joints is utilized in the heat exchanger which consists of plates of austenitic stainless steel to copper [4]. In vessel apparatuses of the International Thermonuclear Experimental Reactor austenitic stainless steel and copper alloy are considered as a chief structure of materials for the first wall and find out systems. The austenitic stainless steel is also utilized in the nuclear surroundings [5].

Innovative joining operation of similar and dissimilar materials is provided by diffusion bonding welding process without producing macroscopic distortion; with minimum dimensional tolerance and no phase transformation or microstructional change occurred during the welding process [6]. A 
diffusion bonding process also permits the production of high- quality joints with little or no need for post weld machining [7]. Design of experimental (DOE) was used in this work to get a suitable number of samples to be tested to characterize the effect of bonding variables (temperature, duration time and applied load) on the diffusion bonding joints. Bilgin (2009) studied the interfacial properties of diffusion bonding of stainless steel type $304 \mathrm{~L}$ with Ti-6Al-4V using $\mathrm{Cu}$ interlayer. This work was applied at temperature range of (820-870) $\mathrm{C}^{\circ}$, time range of (50-90) min. and load of 1Mpa. The joints were examined using SEM, EDS, shear test and micro hardness test. At different conditions to predict optimum conditions of shear strength at $870 \mathrm{C}^{\circ}$, and duration time of $90 \mathrm{~min}$. due to better coalescence [8]. Xiong (2012) studied the diffusion bonding of stainless steel to copper with Tin, Bronze and gold interlayer. The diffusion bonding of two materials was obtained under temperature range of (830-955) $\mathrm{C}^{\circ}$, load 3Mpa and duration time of $60 \mathrm{~min}$. The optimum conditions observed for this work were at $850 \mathrm{C}^{\circ}$ to get tensile strength of 228 $\mathrm{Mpa}$ for $\mathrm{Tb}-\mathrm{Au}$ interlayer. The microstructure of joint was examined using SEM and EDS [9]. Sabetghadam (2010) evaluated the microstructure of diffusion bonded joint between stainless steel 410 and copper using $\mathrm{Ni}$ as interlayer. The bond joints were applied at temperature range of (800950) $\mathrm{C}^{\circ}$, load of $12 \mathrm{Mpa}$ and duration time was 60 minutes in vacuum of $\left(1.3 \times 10^{-2} \mathrm{~Pa}\right)$. The microstructure and phases near bonding interface were examined using optical microscope, SEM and EDS. The result indicated an increase in thickness of reaction layer with an increase in temperature [10]. Kaya (2011) worked on the diffusion bonding of stainless steel with copper by two methods Convential diffusion bonding and non-conventional diffusion bonding by applied external current. The specimens to be bonded were in dimensions of $10 \mathrm{~mm}$. dia. and $35 \mathrm{~mm}$. length. The bonding conditions were $875 \mathrm{C}^{\circ}$, duration time $30 \mathrm{~min}$. and applied load $3 \mathrm{Mpa}$, with heating and cooling rate of $20 \mathrm{C} / \mathrm{min}$. The interface of bonded joints was examined by tensile test and SEM\&EDS. The strength of conventional bonding was $159 \mathrm{Mpa}$ and for nonconventional $169 \mathrm{Mpa}$. The total diffusion of convential was $6.4 \%$ wt. while for non-convential was $9.1 \%$ wt [11]. All previous studies were restricted to the evaluation of the diffusion parameters influence and microstructure on the interface of the diffusion area. But, there are no studies of the characterization of the influence of the diffusion bonding metallurgical transformation on the corrosion behavior of (AISI 304L/pure copper) bonding joints. The present work makes an effort with a contribution to this challenging dilemma.

\section{Experimental}

\subsection{Preparation of Vacuum Diffusion Bonding Unit}

In order to evaluate the sound diffusion bonding of two dissimilar materials of pure copper (OFHC) grade (C10200) and austanitic stainless steel type AISI 304L, the diffusion bonding requires to be applied in vacuum. Joining under vacuum reveals minimum impurity content, even in the case of high reactive metals. Vacuum provides faster and more complete degassing of joined materials and removal of oxides, impurities and contaminants from both surface and bulk materials. The system consists of vacuum diffusion pump, double stage rotary vacuum pump, electrical loading system with capacity of 50 ton, vacuum tube furnance with heating system, vacuum fitting and cooling system for furnace and diffusion as shown in Fig. (1).

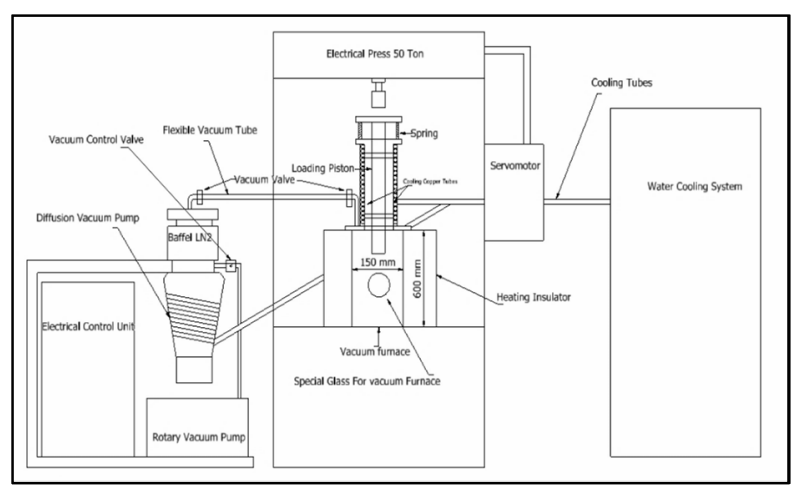

Fig .1. Vacuum Diffusion Bonding Unit.

\subsection{Materials}

Materials used in this work were wrought austenitic stainless steel AISI 304L according to (ASTM volume 01.01) and hard drawn pure copper (OFHC) grade (C10200) according to (ASTM volume 02.01). 
Table 1,

Mechanical properties of two materials used.

\begin{tabular}{lllll}
\hline Materials & Yield strength(MPa) & Ultimate strength (MPa) & Elongation \% & Hardness \\
\hline Stainless 304L & 210 & 564 & 58 & HRB=85 \\
Copper(OFHC) & 230 & 255 & 28 & HB=65 \\
\hline
\end{tabular}

\subsection{Specimens Preperation for Diffusion Bonding Process}

The materials to be joined by diffusion bonding were pure copper(OFHC) and stainless steel 304L. Cylindrical samples of $15 \mathrm{~mm}$ diameter for each lengths were used with $30 \mathrm{~mm}$ and $60 \mathrm{~mm}$ for copper and stainless steel respectively[12]. The mating sample surface was prepared using convential grinding on 1200 grade $\mathrm{SiC}$ papers followed by polishing with diamond paste using fabricated holder to get flat surface . The specimens were cleaned in ultrasonic bath using acetone for $15 \mathrm{~min}$. to remove adhered contaminations and dried in air before bonding.

\subsection{DOE (Design of Expermental)}

\subsubsection{Selection of process parameter (Surface Response)}

The working range for each parameter is given in Table (2). This represents boundary of optimum conditions to be searched according to (0.5-0.8 melting temperature) [6]; (4-13\% $\left.\sigma_{\mathrm{y}}\right)$ applied load and duration time range (15-75) min. from previous works. These ranges are selected according to the recommended optimum ranges of temperature, the duration time and applied load of diffusion bonding welding process [14].

Table 2,

Working ranges of selected parameters.

\begin{tabular}{lcc}
\hline Parameters & Min. & Max. \\
\hline Temperature $\left({ }^{\circ} \mathrm{C}\right)$ & 550 & 750 \\
Duration time $(\mathrm{min})$ & 15 & 75 \\
Applied pressure $(\mathrm{MPa})$ & 10 & 30 \\
\hline
\end{tabular}

\subsubsection{Construction of the experimental design matrix}

The value of coded variables and uncoded variables for experimental design is shown in Table (3).

Table 3,

Experimental Design Matrix.

\begin{tabular}{|c|c|c|c|c|c|c|}
\hline \multirow{2}{*}{$\begin{array}{l}\text { Exp. } \\
\text { Numbers }\end{array}$} & \multicolumn{3}{|l|}{ Coded value } & \multicolumn{3}{|c|}{ Original value } \\
\hline & $\begin{array}{l}\text { Bonding } \\
\text { temp. }(\circ \mathrm{C}) \mathrm{T} 1\end{array}$ & $\begin{array}{l}\text { Bonding } \\
\text { Time(min.)T2 }\end{array}$ & $\begin{array}{l}\text { Bonding } \\
\text { pressure(MPa)T3 }\end{array}$ & $\begin{array}{l}\text { Bonding } \\
\text { temp. }\left(\mathbf{C}^{\circ}\right)\end{array}$ & $\begin{array}{l}\text { Bonding } \\
\text { time(min.) }\end{array}$ & $\begin{array}{l}\text { Bonding } \\
\text { pressure(Mpa) }\end{array}$ \\
\hline 1 & -1 & -1 & -1 & 600 & 30 & 15 \\
\hline 2 & +1 & -1 & -1 & 700 & 30 & 15 \\
\hline 3 & -1 & +1 & -1 & 600 & 30 & 25 \\
\hline 4 & +1 & +1 & -1 & 700 & 30 & 25 \\
\hline 5 & -1 & -1 & +1 & 600 & 60 & 15 \\
\hline 6 & +1 & -1 & +1 & 700 & 60 & 15 \\
\hline 7 & -1 & +1 & +1 & 600 & 60 & 25 \\
\hline 8 & +1 & +1 & +1 & 700 & 60 & 25 \\
\hline 9 & -1.682 & 0 & 0 & 550 & 45 & 20 \\
\hline 10 & +1.682 & 0 & 0 & 750 & 45 & 20 \\
\hline 11 & 0 & -1.682 & 0 & 650 & 45 & 10 \\
\hline 12 & 0 & +1.682 & 0 & 650 & 45 & 30 \\
\hline 13 & 0 & 0 & -1.682 & 650 & 15 & 20 \\
\hline 14 & 0 & 0 & +1.682 & 650 & 75 & 20 \\
\hline 15 & 0 & 0 & 0 & 650 & 45 & 20 \\
\hline 16 & 0 & 0 & 0 & 650 & 45 & 20 \\
\hline 17 & 0 & 0 & 0 & 650 & 45 & 20 \\
\hline 18 & 0 & 0 & 0 & 650 & 45 & 20 \\
\hline 19 & 0 & 0 & 0 & 650 & 45 & 20 \\
\hline 20 & 0 & 0 & 0 & 650 & 45 & 20 \\
\hline
\end{tabular}


where:

$\mathrm{T}_{1}$ : The code value of temperature; $\mathrm{T}_{2}$ : The code value of duration time; $\mathrm{T}_{3}$ : The code value of applied load.

\subsubsection{Tensile Test of Diffusion Bonded Joints}

To evaluate the tensile strength of bonded joints after welding, the bonded joint specimens were sectioned into small specimens for microstructure, mechanical properties tensile test. The tensile strength value was obtained by average value for tests. The tensile test specimens were cut by using wire cutting machine from bonded joints according to (ASTM E8-89), in such a way that the weld zone was positioned at the center of gauge length. The tensile test specimen shown in Fig. (2), was applied by using universal testing machine type WDW 200 E with cross speed $0.1 \mathrm{~mm} / \mathrm{min}$.

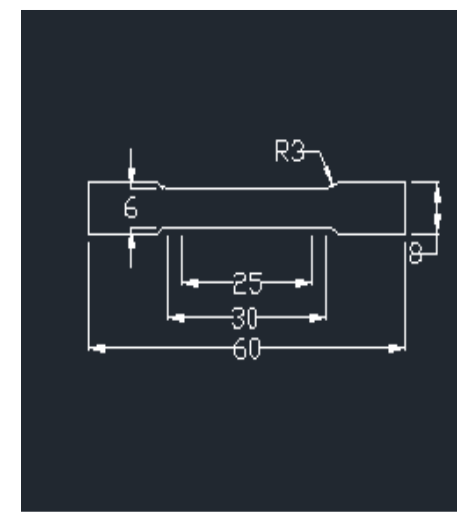

Dimensions $(\mathrm{mm})$ of tensile test specimen with thickness of (6mm) according to ASTM E8-89

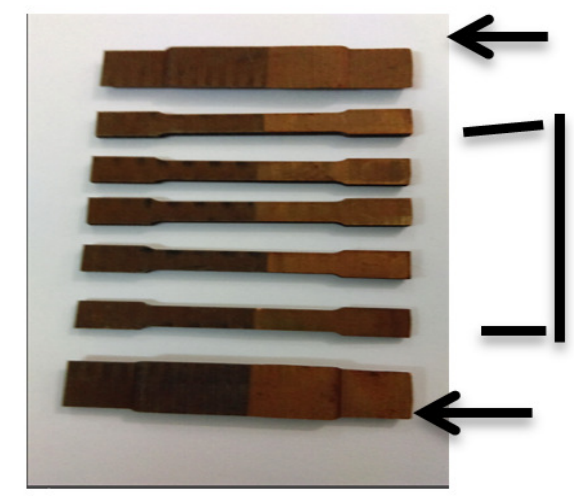

(a)

(b)

\section{Results and Discussions}

\subsection{Tensile Test of Diffusion Bonding Joints}

The bond strength of the bonding joints represents the response for the program Min Tab16. As shown in Fig.3 (A). The results from tensile tests are shown in Table (3). The fracture of most tensile test specimens was occurred in the copper side not at the bond line as shown in Fig.3 (B). This means the bond area is much stronger than copper side; this due to the used of vacuum atmosphere conditions which lead to better coalescence. This results in complete mating of two surfaces, and diffusion of copper atoms leads to good bonding.
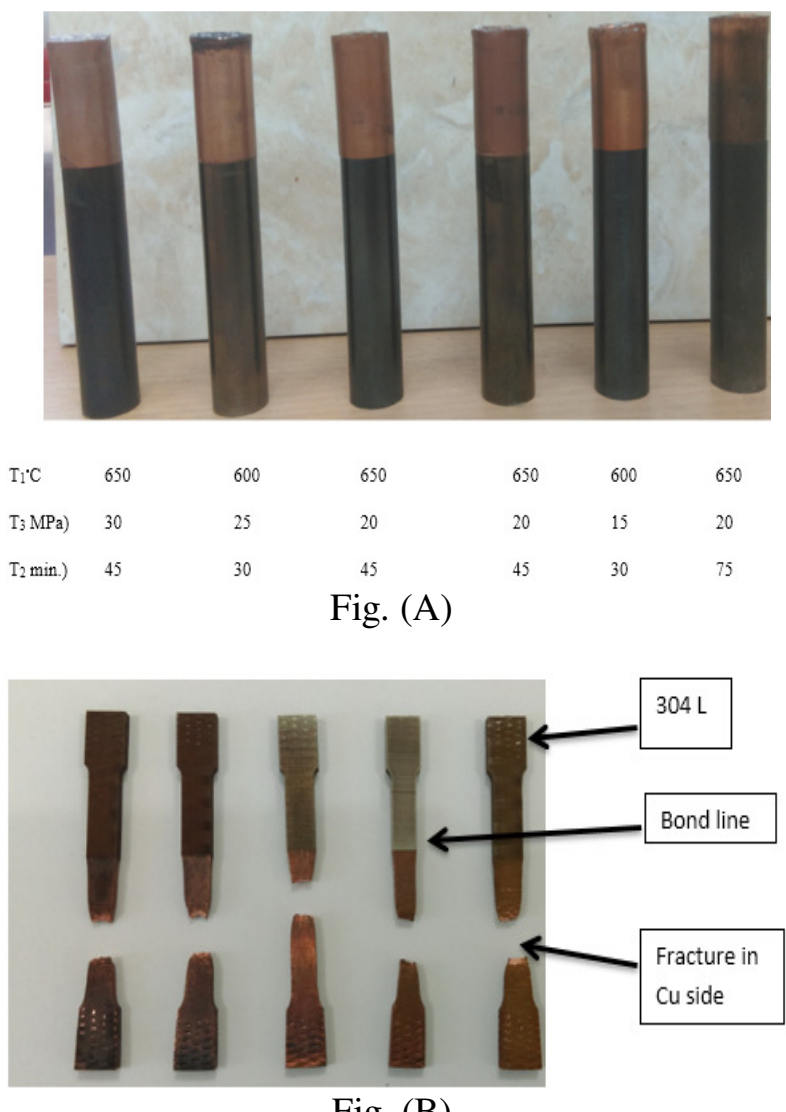

Fig. (B)

Fig. 3. (A) A set of diffusion bonding joints at different bonding conditions. ( B) Fracture of diffusion bonding joints.

Tensile test specimen

Fig. 2. Specimens for Tensile test. 
Table 3,

Results of tensile tests of bonding joints.

\begin{tabular}{lllllll}
\hline $\begin{array}{l}\text { T1 Temp. } \\
(\mathbf{C})\end{array}$ & $\begin{array}{l}\text { T2 Time } \\
\text { (Min.) }\end{array}$ & $\begin{array}{l}\text { T3 stress } \\
\text { (MPa) }\end{array}$ & $\begin{array}{l}\text { Fracture } \\
\text { Stress }(\mathbf{M P a})\end{array}$ & Fracture location & $\begin{array}{l}\text { Ultimate } \\
\text { Strength(MPa) }\end{array}$ & Elongation\% \\
\hline 600 & 30 & 15 & 128.0 & at copper & 178 & 26 \\
700 & 30 & 15 & 30.0 & at interface & 113 & 8 \\
600 & 30 & 25 & 123.0 & at copper & 210 & 44.5 \\
700 & 30 & 25 & 45.0 & at interface & 76 & 5.5 \\
600 & 60 & 15 & 38.0 & at interface & 49 & 3.5 \\
700 & 60 & 15 & 58.0 & at copper & 142 & 11.5 \\
600 & 60 & 25 & 80.0 & at copper & 193 & 22.5 \\
700 & 60 & 25 & 113.0 & at copper & 191 & 12.5 \\
550 & 45 & 20 & 53.0 & at copper & 120 & 4.5 \\
750 & 45 & 20 & 4.8 & at interface & 56 & 16 \\
650 & 45 & 10 & 57.0 & at copper & 138 & 40.5 \\
650 & 45 & 30 & 153.0 & at copper & 210 & 27 \\
650 & 15 & 20 & 128.0 & at copper & 200 & 40.5 \\
650 & 75 & 20 & 127.0 & at copper & 200 & 38.5 \\
650 & 45 & 20 & 110.0 & at copper & 200 & 3.5 \\
650 & 45 & 20 & 49 & at interface & 82 & 42.5 \\
650 & 45 & 20 & 105.0 & at copper & 210 & 44.5 \\
650 & 45 & 20 & 112.0 & at copper & 184 & 24 \\
650 & 45 & 20 & 107.0 & at copper & 173 & 44.5 \\
650 & 45 & 20 & 112.5 & at copper & 225 & \\
\hline
\end{tabular}

\section{4-2 Parametric Analysis of Bond Strength}

The main effect of plot of each variable of (T1, $\mathrm{T} 2$ and T3) on the bond strength is shown in Figure (4). The bond strength increases with an increase in temperature (T1) until reaching maximum value at temperature of $650{ }^{\circ} \mathrm{C}$ and then decreases until reached a temperature of $750{ }^{\circ} \mathrm{C}$. This indicates maximum strength at $650{ }^{\circ} \mathrm{C}$ with higher bond strength than other temperatures values of bonding. The effect of a second variable that is, duration time of bonding (T2) on the bond strength of $15 \mathrm{~min}$. gets on the acceptable bond strength, but when time increases fluctuation in bond strength can be seen until reaches the maximum value of $75 \mathrm{~min}$. Finally, the effect of third variable (T3) is applied load on the bond strength at low values of load. This indicates low bond strength, but the maximum value of bond strength was observed at applied stress of (30 MPa) due to complete mating surface between two bonding metals used.

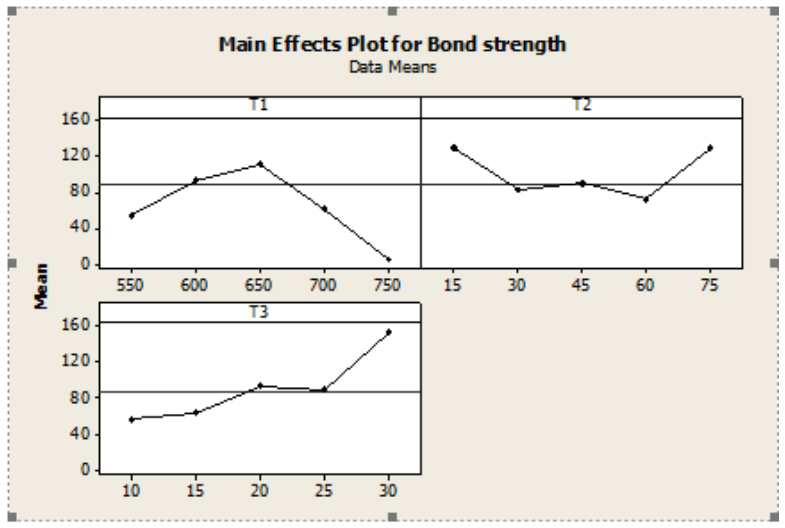

Fig. 5. Main effects on fracture stress.

\subsubsection{Response Surface Regression}

The analysis of results of bond strength versus T1 (Temperature), T2 (Duration time) and T3 (Applied stress) was done using uncoded units of input data. Regression was estimated coefficients for bond strength in order to obtain the significance by calculating (P-level) for each coefficient to determine which of these significant factors have effect on the bond strength. Depending on the significance level $(\alpha=0.05)$, the coefficient with $\mathrm{p}$ - level value is greater than 0.05 which is not significant like (T3, T22, T33, T13 and T23), coefficients which have p-level less than 0.05 like (To, T1, T2, T11and T12) represent the effective values on the bond strength of 
diffusion bonding joints of two materials, therefore the mathematical model of significant parameters may be written as shown in equation (1). $\mathrm{Y}=-1711.34+8.19 \mathrm{~T}_{1}-29.85 \mathrm{~T}_{2}-0.01 \mathrm{~T}_{1}{ }^{2}+$ $0.04 \mathrm{~T}_{1} * \mathrm{~T}_{2}$

\subsubsection{ANOVA Results of Bond Strength}

The analysis of variance (ANOVA) for the bond strength is shown in Table (4); it is made by using Fisher test (F-Test) and results. It can be observed from this table that, the coefficient of R.sq $=92.80 \%$ but the R.sq (Adj.) $=86.32 \%$. The difference between two values of $\mathrm{R}$ is small therefore, this means the three variables (T1, T2 and T3) qualified in variation of bond strength by $(86.32 \%)$ and about of $(13.68 \%)$ due to random error and noise or the effects of other variables. Depending on significance value of (0.05), observed from the table, the total of Pvalue is less than 0.05 therefore the test is significant.

Table 4,

AVONA for bond strength with significant level (0.05).

\begin{tabular}{lllllll}
\hline Source & DF & Seq. (SS) & Adj. SS & Adj.(MS) & F & P \\
\hline Regression & 9 & 28882.0 & 28882.0 & 3209.1 & 14.32 & 0.000 \\
Linear & 3 & 8649.8 & 18994.4 & 6331.5 & 28.26 & 0.000 \\
Square & 3 & 12451.0 & 12451.0 & 4150.3 & 18.52 & 0.000 \\
Interaction & 3 & 7781.2 & 7781.2 & 2593.7 & 11.58 & 0.001 \\
Residual Error & 10 & 2240.6 & 2240.6 & 224.1 & ----- & ----- \\
Lack of Fit & 5 & 1588.2 & 1588.2 & 317.6 & 2.43 & 0.176 \\
Pure Error & 5 & 652.4 & 652.4 & 130.5 & ------ & ----- \\
Total & 19 & 31122.7 & ------ & - & - & - \\
R-Sq. $=92.80 \%$ & R-Sq.(pred)=55.86\% & R-Sq. (Adj)=86.32\% & & & \\
\hline
\end{tabular}

\subsubsection{Optimization of Surface Response (Bond Strength)}

The optimum value of bonding conditions is calculated using the equation (2), to predict the maximum value of bond strength of diffusion bonding joints for various bonding conditions.

$D_{i}=\left(\frac{y_{i}-L_{i}}{T_{i}-L_{i}}\right)^{r}$

where:

$\mathrm{Di}=$ Individual desirability.

$\mathrm{y}_{\mathrm{i}}=$ Response.

$\mathrm{T}_{\mathrm{i}}=$ Target.

$\mathrm{L}_{\mathrm{i}}=$ Lower limit values of the response.

$\mathrm{r}=$ Unit weight factor (usually $=1$ ).

The calculated optimum results are shown in Table (4); optimum bonding conditions was observed at experiment number 12 , with bonding conditions of $650{ }^{\circ} \mathrm{C}, 45 \mathrm{~min}$. and $30 \mathrm{MPa}$ applied stress. The high value of Di equal to (1) represents the maximum value of bond strength and the value of $\mathrm{Di}=0$ represents the minimum value of bond strength [14]. The maximum tensile strength of bonding joint was obtained at the bonding conditions of temperature at $650{ }^{\circ} \mathrm{C}$, duration time of bonding at $45 \mathrm{Min}$. and applied load of complete coalescence at $30 \mathrm{MPa}$. Joint efficiency is attributed to the quality of the joints. Therefore, joint efficiency was estimated. [15] as follow:

Joint efficiency $=153 \mathrm{MPa} / 230 \mathrm{MPa}$ (for copper) $\%=66.5 \%$

Joint efficiency $=153 \mathrm{MPa} / 550 \mathrm{MPa}$ (for stainless steel) $\%=28 \%$

\subsection{Surface and Counter Plots}

The response surface analysis which has two types of plots, the first is three dimensions (3D) representing the surface plot. The second is the two dimensions (2D) indicating the contour plot. The two plots were studied the combination effects of bonding parameters (T1, T2 and T3) on the bond strength of joints. 
Table Ranks of response surface of results.

\begin{tabular}{|c|c|c|c|c|c|c|}
\hline No. & T1 $\left({ }^{\circ} \mathbf{C}\right)$ & T2 (Min.) & T3 (MPa.) & Fracture stress. (MPa.) & Di & Rank \\
\hline 1 & 600 & 30 & 15 & 128.0 & 0.8313 & 2 \\
\hline 2 & 700 & 30 & 15 & 30.0 & 0.1700 & 18 \\
\hline 3 & 600 & 30 & 25 & 123.0 & 0.7975 & 4 \\
\hline 4 & 700 & 30 & 25 & 45.0 & 0.2712 & 16 \\
\hline 5 & 600 & 60 & 15 & 38.0 & 0.2240 & 17 \\
\hline 6 & 700 & 60 & 15 & 58.0 & 0.3589 & 13 \\
\hline 7 & 600 & 60 & 25 & 80.0 & 0.5074 & 12 \\
\hline 8 & 700 & 60 & 25 & 113.0 & 0.7300 & 5 \\
\hline 9 & 550 & 45 & 20 & 53.0 & 0.3252 & 15 \\
\hline 10 & 750 & 45 & 20 & 4.8 & 0.000 & 20 \\
\hline 11 & 650 & 45 & 10 & 57.0 & 0.3522 & 14 \\
\hline 12 & 650 & 45 & 30 & 153.0 & 1 & 1 \\
\hline 13 & 650 & 15 & 20 & 128.0 & 0.8313 & 2 \\
\hline 14 & 650 & 75 & 20 & 127.0 & 0.8245 & 3 \\
\hline 15 & 650 & 45 & 20 & 110.0 & 0.7098 & 8 \\
\hline 16 & 650 & 45 & 20 & 49 & 0.5209 & 11 \\
\hline 17 & 650 & 45 & 20 & 105.0 & 0.6761 & 10 \\
\hline 18 & 650 & 45 & 20 & 112.0 & 0.7233 & 7 \\
\hline 19 & 650 & 45 & 20 & 107.0 & 0.6896 & 9 \\
\hline 20 & 650 & 45 & 20 & 112.5 & 0.7267 & 6 \\
\hline
\end{tabular}

\subsubsection{Effect of Temperature and Duration Time on Bond Strength}

Figures (5 a and b) indicate 3D surface and 2D contour plots which show combination effect of $\mathrm{T} 1$ (temperature) and T2 (duration time) at constant level (middle value) of T3 (applied stress) equal to (20 MPa.) on the bond strength. Figure. ( 5 a) shows the effect of temperature and duration time on the surface response bond strength. It can be observed from this, the bond strength increases with an increase in temperature and duration time but the effect of temperature is more effective than duration time. The optimal bonding conditions are temperature of $650{ }^{\circ} \mathrm{C}$ and duration time at $45 \mathrm{~min}$. The increase in temperature above $650{ }^{\circ} \mathrm{C}$ leads to rapid grain growth which leads to low bond strength [16]. Fig. (5 b) represents the 2D contour plot for temperature with duration time. It indicates that the maximum bond strength observed at minimum temperature and duration time but it cannot be result in sound diffusion bonding joints. The optimum bonding condition at the range of 120$180 \mathrm{MPa}$ as shown in Fig. $(5 \mathrm{~b})$. The combinations effect of temperature and duration time in contour was observed at maximum temperature of $650{ }^{\circ} \mathrm{C}$ and maximum duration time of $45 \mathrm{~min}$., due to complete coalescence between two coupling surface and high diffusion rate.

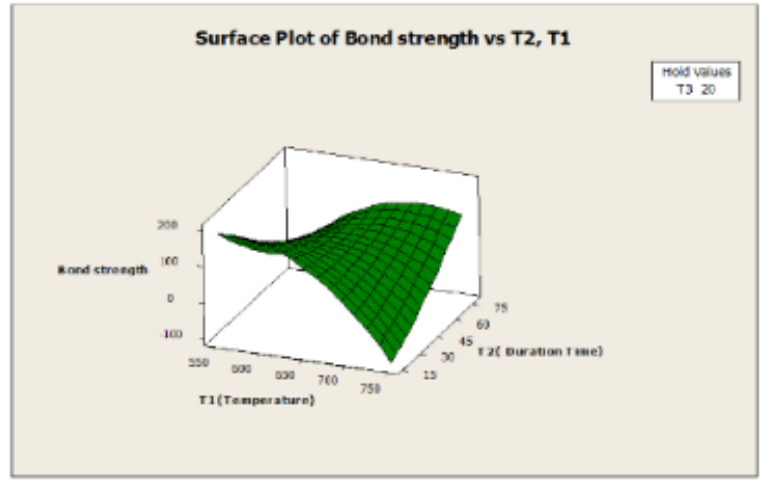

(a)

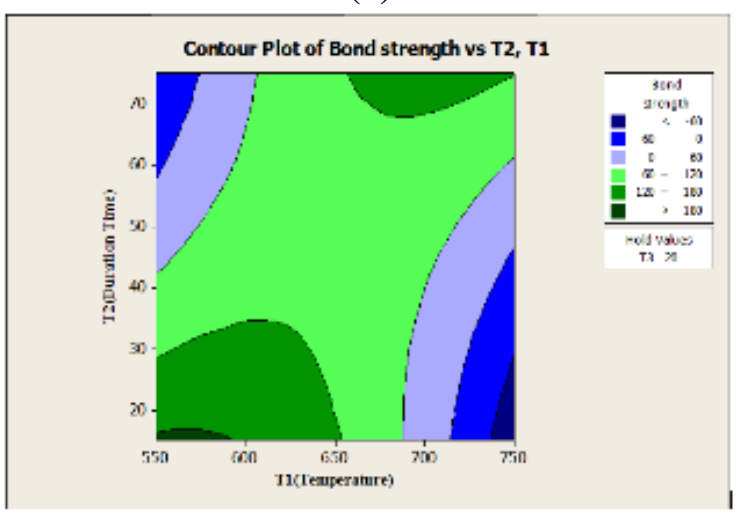

(b)

Fig. 5. Effect of temperature and time on bond strength (a) 3D surface plot (b) 2D contour. 


\subsubsection{Effect of Temperature and Applied Stress on Bond Strength.}

Figures (6 a and b) illustrate combination effects of temperature and applied stress on the bond strength. Figure ( 6 a) shows gradual increase in bond strength until reached maximum value at load of $30 \mathrm{MPa}$. The bonding load was applied in order to secure a tight contact between the bonding surface and a vital condition for the interdiffusion atoms of metals jointed. If the applied stress is less than the optimum value, then the bond strength decreases. The optimum bonding temperature can be seen at $650{ }^{\circ} \mathrm{C}$ and at maximum applied load of $30 \mathrm{MPa}$. The effect of temperature on bond strength is more effective than the effect of applied load and the higher bond strength is $30 \mathrm{Mpa}$.

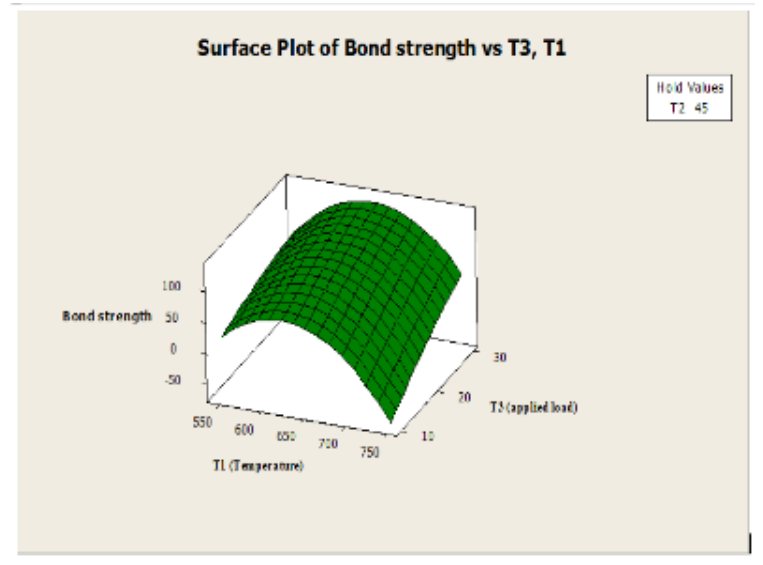

(a)

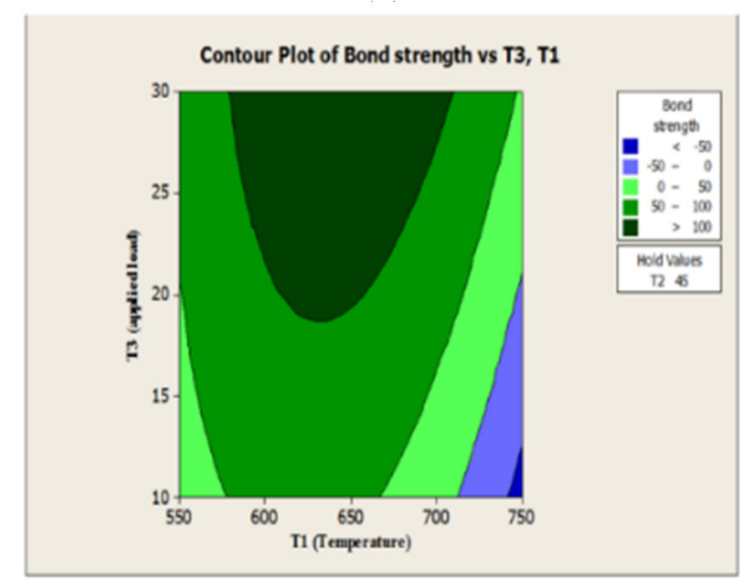

(b)

Fig. 6. Effects of temperature and applied stress on bond strength (a) 3D surface plot (b) 2D contour plot.

\subsubsection{Effect of Time and Applied Stress on Bond Strength.}

The effect of the two variables of duration time (T2) and applied stress (T3) on the surface response bond strength is shown in Figures (7) $a$ and $b$. Fig. (7 a), shows higher effect of duration time than applied load. The right region of plot shows high change in applied stress up to $30 \mathrm{MPa}$. These results are combined with the effect of duration time on the bond strength, when time increases until reached $45 \mathrm{~min}$. with an increase in applied stress to reach $30 \mathrm{MPa}$. At this point maximum value of bond strength is observed. Fig. (7 b) shows combination effects of high applied stress of $30 \mathrm{MPa}$ and high duration time of $45 \mathrm{~min}$. to get optimum value of maximum value of bond strength. Mating surfaces are expanding almost instantaneously. When the applied load increases more than the increase in temperature this leads to plastic deformation and doesn't get sound bonding joint between the two materials used [17].

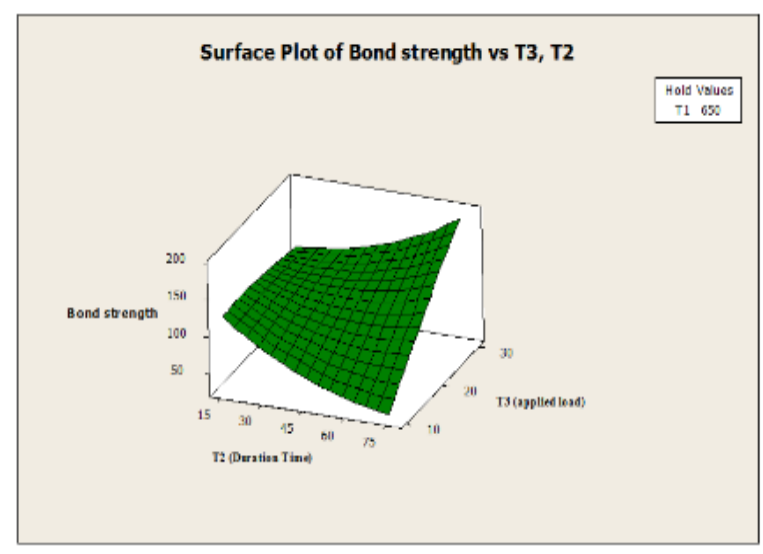

(a)

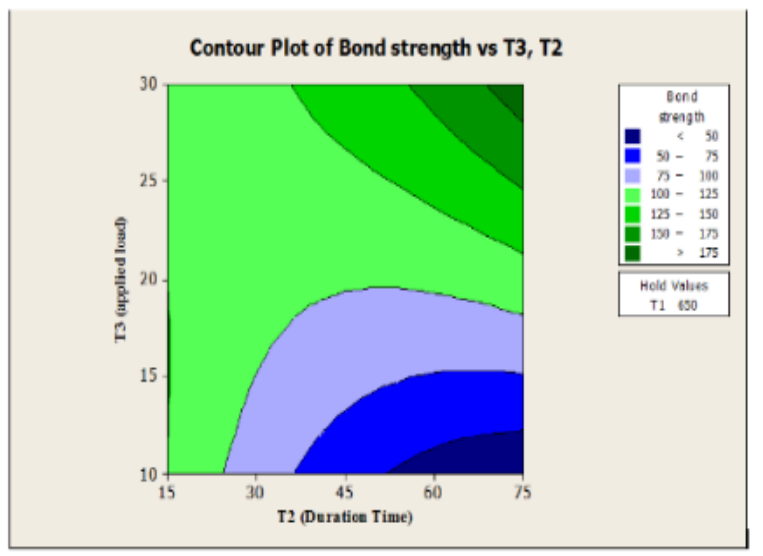

(b)

Fig. 7. Effects of time and applied stress on bond strength (a) 3D surface plot (b) 2D contour plot. 


\section{Conclusions}

1. The dissimilar diffusion bonding joints show lower tensile strength than the base material of hard drawn pure copper (OFHC) side and the maximum bond strength is $153 \mathrm{MPa}$.

2. Vacuum diffusion bonding unit has been successfully prepared and reached vacuum approximately of $\left(1.5 * 10^{-5} \mathrm{mbr}\right)$.

3. The maximum tensile strength of diffusion bonding joint was observed for diffusion bonding joint at optimum bonding conditions of $650{ }^{\circ} \mathrm{C}, 45 \mathrm{~min}$., and applied stress of 30 $\mathrm{MPa}$, annealed at temperature of $800{ }^{\circ} \mathrm{C}$, for 30 min.

4. The equation represent the effect of bonding conditions between hard drawn copper and austenitic stainless steel 304L with significant effects of bonding parameters was:

$\mathrm{Y}=-1711.34+8.19 \mathrm{~T} 1-29.85 \mathrm{~T} 2-0.01 \mathrm{~T} 12+$ $0.04 \mathrm{~T} 1 * \mathrm{~T} 2$

5. The strong effects of diffusion bonding parameters are temperature $>$ duration time $>$ applied load.

6. The efficiency of optimum bonding joint was higher as compared with hard drawn copper and lower as compared with austenitic stainless steel.

\section{References}

[1]J. C., Lippod Koteki D. J, "Welding metallurgy and weldability of stainless steel". New Jersey: Wiley (2005).

[2]N. K. Srinivasan, Welding Technology, Fourth edition, Romesh Chander Khanna, Khanna (2012).

[3]D. Feron, "Corrosion behavior and protection of copper and Aluminum alloys in seawater", Wood head Publishing limited and CRC press LLC, (2007).

[4]K. Bhanumurthy, D. Joyson, A. Laik, "Diffusion bonding of nuclear materials", Brac nem letter, (2013), Issuf no. 331.

[5]R.K.Roy, S.Singh "Joining of 304SS and pure copper by rapidly solidified $\mathrm{Cu}$-based braze alloy", Fusion Engineering and Design, (2011) 452-455.

[6]Kunda S., Chatterjee S., Mechanical Properties of Diffusion Bonded Joints between Titanium and Stainless Steel with Nickel interlayer, Material science and Engineering, (2007).

[7]J. Grum, Slabe J. M," The use of design and response surface methology for fast determination of optimal heat treatment conditions of different Ni-co-Mo surface roughness layers", Journal of Material Processing Technology, (2014).

[8]N. Ozdemir, B. Bilgin, Interfacial properties of diffusion bonded Ti-6Al-4V to AISI 304 stainless steel bt inserting copper interlayer, Journal of Advanced Manufacturing Technology, (2009).

[9]Jiang-tao Xiong, Diffusion bonding of stainless steel to copper with Tin Bronze and Gold interlayer, Journal of Material Engineering and Performance, (2012).

[10] H. Sabetghadam, A. Zarei Hanzaki, Microstructure Evaluation of $410 \mathrm{SS} / \mathrm{Cu}$ Diffusion bonded joint, Journal of Material science and Technology, (2010).

[11] Yakop Kaya, Nizamettin Kahraman, Anovel approach of diffusion bonding of copper to stainless steel, Journal of Engineering Manufacture, (2011).

[12] Ahmed Ali Akber Akber, "Diffusion Bonding of Oxygen High Conductivity Copper to Austenitic Stainless Steel" PhD thesis, University of Technology, (1996).

[13] Rohit Garg "Effect of process parameters on performance measures of wire electrical discharg machining", Ph.D. Thesis, Mechanical engineering department, National institute of technology, Kurukshetra, (2010).

[14] Montgomery, D. C. and Runger, G. C. Applied statistics and probability for engineers, John Wiley and Sons. (2010).

[15] S.Assarzadeh and Ghoreishi, Statistical Modeling and Optimization of the EDM Parameters on Wc-6\% Co Composite through hybrid response surface methodology- desirability function approach, International Journal of Engineering Science and Technology, (2013).

[16] M. Balasubramanian, Application of BoxBehbken design of fabrication of titanium alloy and 304 stainless steel joints with silver interlayer, Materials and Design, (2015).

[17] Pilling J., Solid state of superplastic A A 7475, Materials Science and Technology, (1987). 


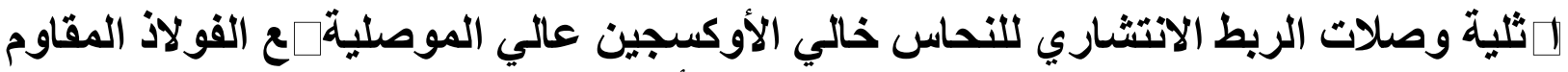 304L}

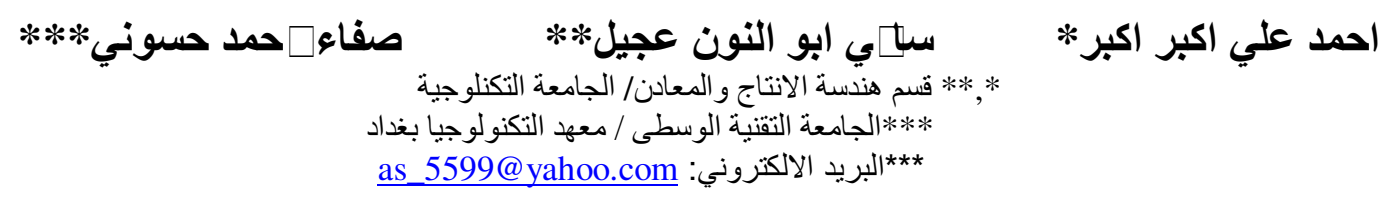

يتضمن البحث تحديد الظروف المثالية للحام الانتشاري المباشر للنحاس خالي الأوكسجين_عالي الموصلية مع الصلب المقاوم للصدأ

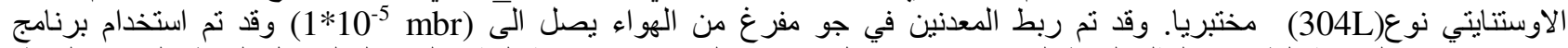

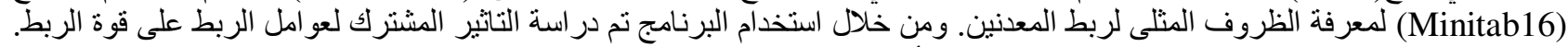

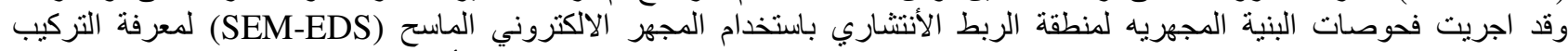

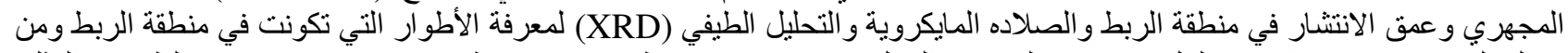

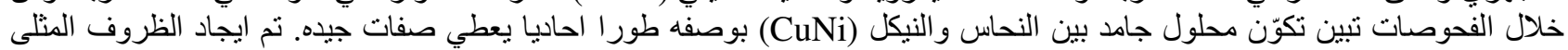

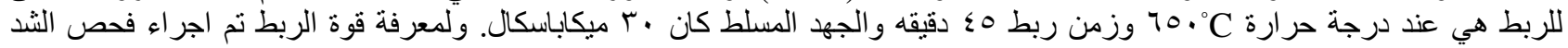

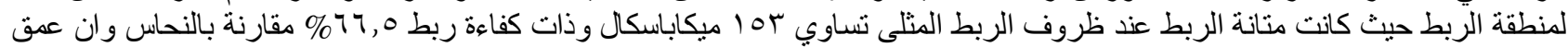

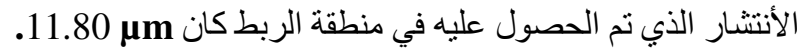

